\title{
Revisão: coberturas comestíveis protetoras em frutas: fundamentos e aplicações
} Review: edible protective coatings for fruits: fundamentals and applications

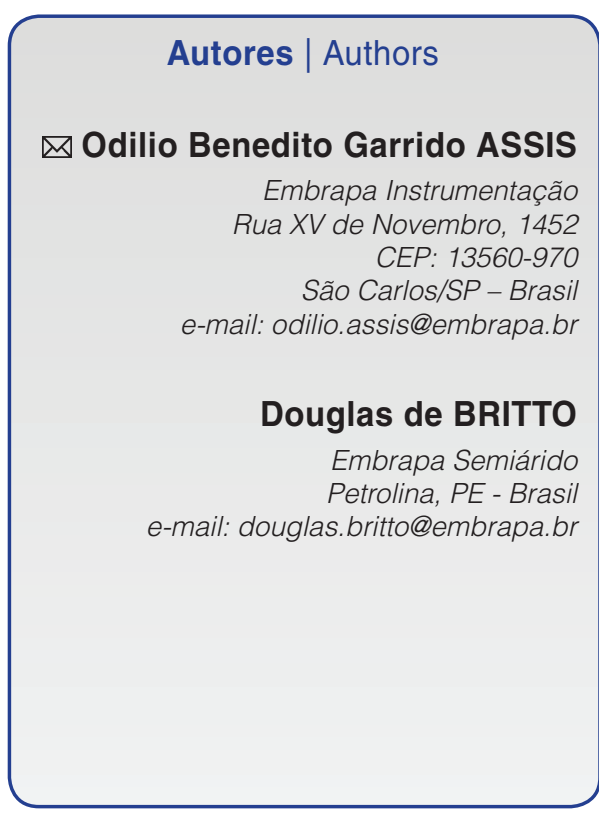

\ Autor Correspondente / Corresponding Author

Recebido / Received: 05/12/2013 Aprovado / Approved: 16/07/2014 Publicado / Published: jun./2014

\section{Resumo}

O emprego de coberturas comestíveis na conservação de frutas na condição pós-colheita, sejam intactas ou minimamente processadas, tem sido preconizado como uma tecnologia emergente e de grande potencial, principalmente para aplicações sobre frutas de origem tropical. Diversos biopolímeros têm sido avaliados na formulação dessas coberturas e, neste texto, apresentamos, de forma geral, os principais conceitos físico-químicos envolvidos no processo, com o objetivo de subsidiar uma escolha que possa gerar uma maior eficiência da cobertura formada. Alguns exemplos de aplicação, com base na literatura, são apresentados a título ilustrativo. É importante notar que não há uma cobertura "universal", ou seja, uma formulação que possa ser aplicada a qualquer fruta indiscriminadamente. A escolha do material apropriado dependerá das características da fruta, do biopolímero e dos objetivos almejados para o revestimento.

Palavras-chave: Coberturas comestiveis; Biopolímeros; Conservação pós-colheita.

\section{Summary}

The use of edible coatings to preserve post-harvest fruits in the intact or slightly processed forms, has been advocated as an emerging technology with great potential for application in fruits, especially those of tropical origin. Several biopolymers have been evaluated in formulating these coatings and this review presents the main physicochemical concepts related to the coating formed in a general way. Some examples of their applications, available in the literature, are also presented for illustrative purposes. It is important to note the absence of a "universal" coating, that is, a formulation suitable for application to any fruit indiscriminately. The ideal choice depends on the fruit, the biopolymer and the aims targeted for the coating.

Key words: Edible coatings; Biopolymers; Post-harvest conservation. 


\section{Introdução}

Os métodos normalmente empregados para a conservação de frutas intactas na condição pós-colheita, ou após alguma etapa mínima de processamento, fazem uso, prioritariamente, de refrigeração associada ou não a embalagens com atmosferas controladas. As condições mais comuns, e de comprovada eficiência, têm por base procedimentos nos quais a temperatura é reduzida logo após a colheita e a cadeia do frio - a uma temperatura apropriada para cada produto - é mantida, preferencialmente em ambiente com alta umidade relativa, até a comercialização final (BARBOSA-CÁNOVAS et al., 2003; COSTA e CLEMENTE, 2012).

Na prática, contudo, a manutenção e o controle efetivo da temperatura em todas as etapas da cadeia não é uma condição trivial, o que é observado mesmo em países ditos desenvolvidos, nos quais as infraestruturas para este fim são consideravelmente superiores às nossas (RODRIGUE e NOTTEBOOM, 2009).

Desta forma, uma tecnologia alternativa cada vez mais divulgada e avaliada como um procedimento viável para elevar o tempo de vida de frutas e hortaliças, processadas ou não, é o emprego de coberturas comestíveis protetoras. Esses revestimentos não têm como objetivo substituir o uso dos materiais convencionais de embalagens ou mesmo eliminar definitivamente o emprego do frio, mas sim o de apresentar uma atuação funcional e coadjuvante, contribuindo para a preservação da textura e do valor nutricional, reduzindo as trocas gasosas superficiais e a perda ou ganho excessivo de água. Ao promover alterações na permeação e, por conseguinte, alterar a atmosfera interna, alguns autores consideram o efeito dessas coberturas similares aos conseguidos pelas embalagens com atmosfera modificada (PARK, 2005; TURHAN, 2010); essas coberturas têm sido indicadas, principalmente, para produtos com alta taxa de respiração (ASSIS et al., 2008).

As coberturas ditas 'comestíveis' são aplicadas ou formadas diretamente sobre a superfície das frutas, configurando membranas delgadas, imperceptíveis a olho nu e com diversas características estruturais, que são dependentes da formulação da solução filmogênica precursora. Como estas coberturas passam a fazer parte do alimento a ser consumido, os materiais empregados em sua formação devem ser considerados como GRAS (Generally Recognized as Safe), ou seja, serem atóxicos e seguros para o uso em alimentos (FDA, 2013). Cabe ressaltar que essas coberturas têm sido erroneamente denominadas de "biofilmes", termo este totalmente inapropriado a este tipo de material ou aplicação ${ }^{1}$.

\footnotetext{
"Biofilme" é um termo já consolidado em Biologia e em Ciências Hídricas, de uso específico para a designação de colônias de bactérias imobilizadas sobre uma superfície sólida. São estruturas vivas organizadas, embebidas em matrizes poliméricas e dinâmicas, ou seja, apresentam alterações, como crescimento ao longo do tempo.
}

\subsection{Tipos de coberturas}

As matérias-primas empregadas na formação das coberturas e revestimentos comestíveis podem ter origem animal ou vegetal, ou formarem um composto com a combinação de ambas. Polissacarídeos, ceras (lipídios) e proteínas são as classes de materiais mais empregados, e a escolha, como veremos, depende fundamentalmente das características do produto a ser revestido e do principal objetivo almejado com o revestimento aplicado.

Atualmente, existe a tendência de classificar os materiais empregados nos revestimentos em duas amplas categorias: hidrofóbicos e hidrofílicos (ASSIS et al., 2008; ZARITZKY, 2011), que podem ser genericamente assim definidos como:

Hidrofílicos: materiais com estruturas nas quais há a predominância de grupos amino ou hidroxila e carboxila $\left(\mathrm{OH}, \mathrm{COO}^{-}, \mathrm{NH}_{3}\right)$ caracterizados por ligações covalentes polares. Em função das características desses grupos, a cadeia carbônica apresenta sítios parcialmente carregados positivamente e outros carregados negativamente. Essa característica da estrutura química favorece o acúmulo e o rearranjo de moléculas polares, e principalmente da água, em torno desses sítios. Alguns exemplos destes materiais são os polissacarídeos, como a celulose, a quitina, a goma xantana, a goma guar, a pectina, o amido e os polissacarídeos polieletrólitos, como a carboximetilcelulose, a quitosana, o alginato, etc. Os materiais hidrofílicos normalmente apresentam boa solubilidade em meio aquoso, favorecendo uma melhor dispersão do soluto e uma formação mais homogênea do filme. Dependendo da estrutura química, podem formar géis ou até mesmo requerer alterações químicas para uma completa solubilização.

Hidrofóbicos: materiais caracterizados por moléculas nas quais predominam estruturas cujas ligações tendem a ser eletricamente neutras, ou seja, não configuram regiões polares definidas. Incluem grupos alquilas $\left(\mathrm{CH}_{3}, \mathrm{CH}_{2}-\mathrm{CH}_{3}\right.$, etc) e aromáticos. Na presença de água esses materiais tendem a se aglomerarem e excluir as moléculas polares de sua redondeza. Nesta categoria, encontram-se as proteínas hidrofóbicas (predominância de substituintes apolares), óleos e ácidos graxos, em que predominam substituintes de cadeia alifática, parafinas, alcoóis de cadeia longa, etc. Para esta classe de materiais, os solventes adequados devem ser mais apolares, como o álcool, a acetona e o hexano.

As coberturas hidrofílicas são mais indicadas para superfícies fatiadas, frutas com aspectos brilhantes que apresentem alta molhabilidade ou presença de cargas superficiais. Por terem afinidade por água, as coberturas hidrofílicas preservam o aspecto hidratado, mantendo por mais tempo a superfície brilhante. As formulações hidrofóbicas, por sua vez, são indicadas para 
Revisão: coberturas comestíveis protetoras em frutas: fundamentos e aplicações

ASSIS, O. B. G. e BRITTO, D.

o revestimento de frutas com alta taxa de transpiração, nas quais a degradação ocorre essencialmente por perda de água, levando a desidratação e alteração do aspecto superficial.

Essas indicações, contudo, são bastante genéricas e demais aspectos físico-químicos das frutas a serem revestidas devem ser avaliados para que a seleção de uma formulação tenha um resultado satisfatório.

\section{Deposição e formação de filme superficial}

Ao imergir uma fruta em uma solução filmogênica, a cobertura se forma pela deposição das espécies poliméricas dissolvidas no meio, estabelecendo ligações, fracas e fortes, com a superfície da fruta. Diversos modelos têm sido propostos para a deposição de estruturas poliméricas e subsequente formação de filmes sobre superfícies sólidas. Nesses modelos, as características do absorvente (em nosso caso, a casca) e do absorvato (compostos diluídos na solução filmogênica) são as que definem que tipo de mecanismo será predominante na formação da cobertura (MYERS, 1991; PARIA e KHILAR, 2004). De um modo geral, podem-se distinguir cinco interações passíveis de ocorrência ao mergulhar uma fruta em uma solução de polímeros dissolvidos:

a) Ligação de hidrogênio: entre adsorvente e adsorvato. Predominam em superfícies hidrofílicas ou materiais com alta densidade de grupos polares, como as hidroxilas $(-\mathrm{OH})$ e a amina $\left(-\mathrm{NH}_{2}\right)$;

b) Interação hidrofóbica: ocorre por afinidade entre grupos hidrofóbicos das moléculas em ambiente aquoso e os grupos hidrofóbicos presentes na superfície sólida;

c) Interação por forças dispersivas: ocorre via forças intermoleculares, como as de London-van der Waals, que estabelecem interações fracas e de curto alcance entre moléculas de adsorvato e adsorvente.

d) Polarização de elétrons $\pi$ : ocorre quando o adsorvato contém um núcleo aromático e a superfície possui sítios carregados positivamente, mecanismo este de baixa ocorrência em sistemas orgânicos;

e) Interação eletrostática: ocorre devido à interação de espécies iônicas carregadas permanentemente de cargas opostas; é considerada no caso em que o polímero em solução apresenta caráter polieletrolítico com grupos salinos aniônicos (-COO-Na+) ou grupos salinos catiônicos $\left(-\mathrm{NH}_{4}{ }^{+} \mathrm{Cl}^{-}\right)$.

Na prática, todos os tipos de interações podem ocorrer simultaneamente e em intensidades variadas, embora, em função das características dos materiais em solução e da superfície, haja a predominância de um mecanismo. Podemos generalizar a formação do recobrimento segundo a sequência ilustrativa da Figura 1.

\section{Características superficiais das frutas}

Uma fruta apresenta basicamente três camadas distintas: o endocarpo, que constitui a camada mais interna e que, geralmente, envolve as sementes; o mesocarpo, caracterizado por uma camada intermediária, suculenta, que tem a função de armazenar substâncias de reserva, e o epicarpo ou exocarpo, a camada externa, normalmente membranácea e fibrosa, popularmente conhecida como casca.

O exocarpo é normalmente recoberto por uma cutícula constituída de material lipídico em formato de camadas. Na maioria das frutas, as células epidérmicas se encontram sob uma cera epicuticular que tem como composição uma mistura complexa de diferentes ésteres (a)

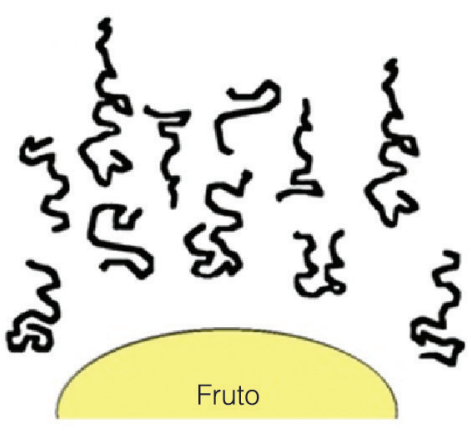

(b)

Processo de adsorção

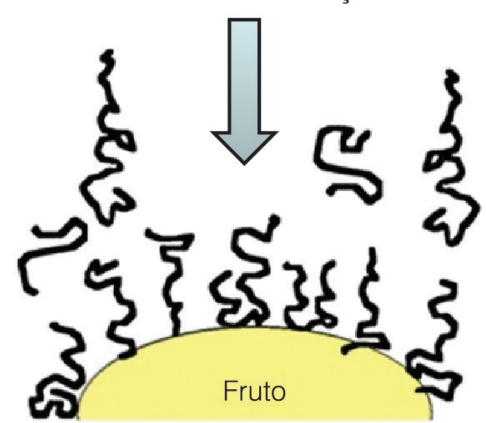

Evaporação do solvente e reticulação ou cura

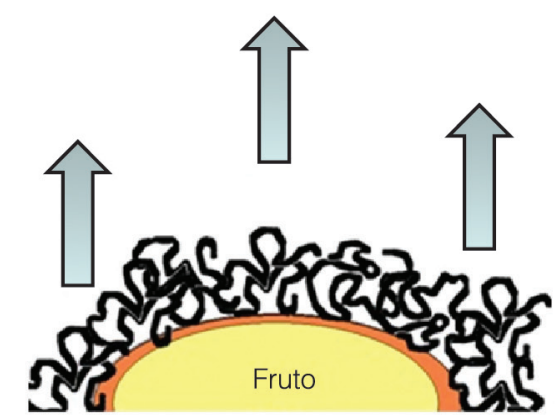

Figura 1. Sequência ilustrativa da formação de uma cobertura comestível. Em (a), temos a imersão do fruto em solução filmogênica (polímeros em solução). Em (b), ocorre a atração entre o absorvato (composto diluído na solução filmogênica) e o absorvente (casca) por um dos possíveis mecanismos. Após um período de deposição, o fruto é removido da solução e, por meio da evaporação do solvente, ocorre a reticulação do polímero, configurando a formação da cobertura (c). 
de ácidos graxos e alcoóis de cadeias longas associados a ácidos graxos e alcanos com forte caráter hidrofóbico (CHITARRA e CHITARRA, 2005). No exocarpo também há a presença de microporos que o tornam permeável à passagem de líquidos e solutos, e aberturas maiores, como estômatos e lenticelas, que permitem uma maior troca gasosa com o ambiente, caracterizando assim a respiração e a transpiração.

O grau de hidrofobicidade de uma casca pode ser avaliado por técnicas específicas, como a medida da molhabilidade, definida pelo ângulo que faz uma gota de água em contato com a superfície. Em análises preliminares realizadas sobre algumas frutas climatéricas, observou-se, por exemplo, que após a colheita a pera apresenta uma superfície com grau de hidrofobicidade superior ao da maçã, que é mais hidrofóbica, por sua vez, do que a goiaba (ASSIS, 2011). Contudo, essas características mudam significativamente ao longo do tempo, em consequência das alterações físico-químicas superficiais decorrentes do amadurecimento, como a degradação da clorofila, a polimerização dos carotenoides ou as mudanças nas características texturais, como desidratação e formação de rugosidade na casca, o que altera as propriedades superficiais, levando a uma maior molhabilidade (hidrofilicidade) com o tempo.

Considerando-se que as forças envolvidas nas interações hidrofóbicas são da ordem de seis a oito vezes superiores às forças iônicas quando medidas em meio aquoso (KEATS, 2000), materiais com características similares teriam assim maior afinidade. Ou seja, um material hidrofóbico estabelece forte interação com uma superfície hidrofóbica, assim como um material hidrofílico adere bem sobre uma superfície hidrofílica. Desta forma, pode-se, em princípio, indicar que para os exemplos citados, uma cobertura constituída por material mais hidrofóbico é a ideal para o revestimento de goiabas, um material intermediário para maçãs e um mais hidrofílico para as peras.
A cinética de absorção tem também forte dependência da natureza do absorvato e da superfície absorvente. Se estes tiverem em solução cargas opostas, a razão de absorção será bastante rápida, atingindo em curto espaço de tempo um equilíbrio do material depositado (PARIA e KHILAR, 2004). No caso das interações hidrofóbicas, estas são regidas essencialmente por forças entrópicas, o que pode ser entendido, de forma simplificada, como um aumento da entropia no sistema decorrente do deslocamento das moléculas de água presentes no absorvente em função do movimento e da consolidação por atração entre as espécies hidrofóbicas (HERZFELD e OLBRIS, 2002). Assim, podemos delinear um modelo no qual a formação da cobertura por forças hidrofóbicas será por um "ancoramento" inicial, seguido por uma acomodação, ou conformação, da espécie polimérica após a desidratação dos sítios superficiais da casca (Figura 2). Em outras palavras, a deposição não segue necessariamente uma cinética de primeira ordem.

O processo também pode sofrer alterações com a mudança da temperatura. Do ponto de vista termodinâmico, aumentando-se a temperatura, aumenta a energia cinética média das moléculas reagentes. 0 aumento da energia eleva a probabilidade das cadeias entrarem em contato com o substrato, elevando a taxa de deposição. Demais fatores, como concentração, pressão parcial, aumento da superfície de contato e força iônica, devem ser levados em consideração para uma análise rigorosa.

Processos como esses, de formação de filmes por deposição espontânea e formação de camadas poliméricas, têm recebido o nome científico de "automontagem", como tradução livre do inglês "selfassembly" (PATERNO et al., 2001), sendo que diversos modelos matemáticos são passíveis de aplicação para o entendimento dos mecanismos que ocorrem em uma automontagem (PELESKO, 2007).
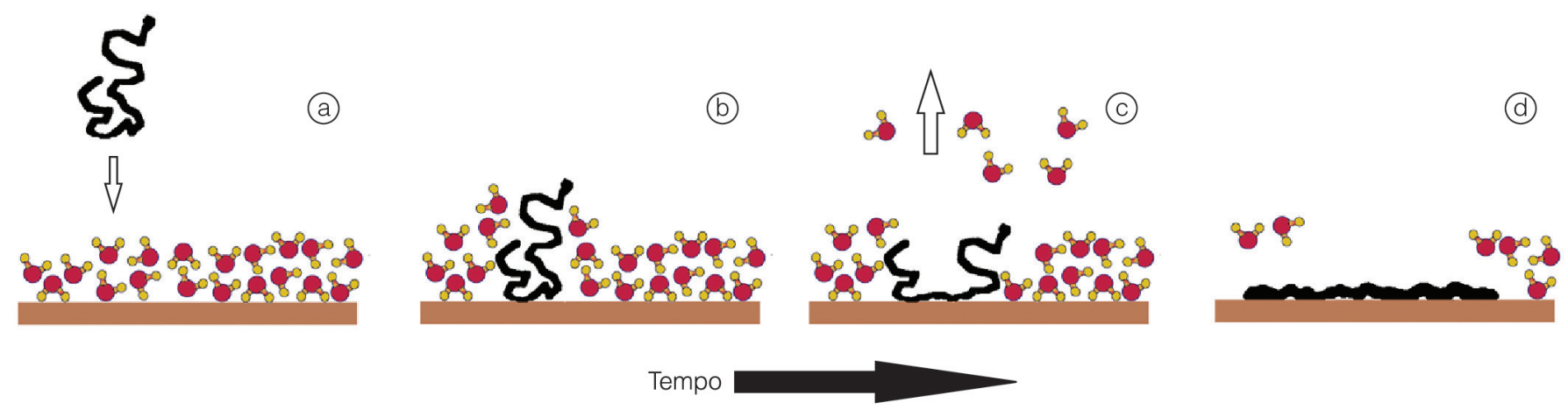

Figura 2. Modelo de conformação de uma única cadeia polimérica: em (a), a atração para a superfície do fruto; em (b), um ponto inicial de ancoramento. A partir da desidratação da superfície (c), o polímero tende a se conformar sobre a superfície, aumentando a área de contato por interação e afinidade por sítios específicos (d). 


\section{Modos de aplicação}

A técnica mais comum e que tem se mostrado mais eficiente na formação de coberturas é a imersão. Embora o uso de pincel (HARALAMPU, 1990; CHLEBOWSKASMIGIEL et al., 2007) e o spray também tenham sido utilizados para alguns casos (ANDRADE et al., 2012), a imersão é o procedimento que garante que toda a superfície entre em contato com a solução filmogênica e uma leve agitação permite o desprendimento de bolhas, possibilitando uma deposição mais homogênea. Uma sequência lógica de formação de cobertura pode então ser resumida segundo o esquema ilustrativo da Figura 3.

Cabe observar que, para alguns materiais, como as proteínas, os filmes formados são extremamente frágeis e de baixa aderência. Nestas formulações, a adição de plastificantes é indicada para conferir uma maior plasticidade e favorecer uma melhor adesão. Como a fruta é um órgão vivo e, ao longo do armazenamento passa por processos fisiológicos que geram pequenas alterações de volume e textura, as coberturas devem apresentar uma flexibilidade mínima o suficiente para acompanhar essas pequenas alterações sem geração de danos estruturais, como trincas ou destacamento. Os plastificantes mais empregados são tipicamente os polióis, como o glicerol, o poli(etilenoglicol) e o sorbitol. Recentemente, compostos proteicos plastificados com ácido oleico têm sido empregados com sucesso na formação de coberturas comestíveis (VARGAS et al., 2009; SCRAMIN et al., 2011).

A adição de plastificante deve ser feita com parcimônia, considerando-se que a presença de moléculas com ação plastificante na matriz polimérica não altera somente as propriedades mecânicas, mas interfere na molhabilidade e na permeação dos filmes formados. As moléculas do plastificante reduzem as forças intermoleculares facilitando o movimento relativo das cadeias. Com o aumento da concentração de plastificante, o espaço entre as cadeias se eleva e a difusão de gases é facilitada (BANKER, 1966; SCRAMIN et al., 2011). A penetração de moléculas de água para o interior do filme também é facilitada, o que leva a uma solvatação em certos sítios polares, gerando um intumescimento da cobertura. Essas alterações estruturais reduzem as propriedades de barreira e a aderência (ASSIS e SILVA, 2003), e facilitam a proliferação de fungos. Assim, elevadas adições de plastificantes devem ser evitadas, as quais, muitas vezes, inviabilizam o uso da formulação como formadora de cobertura protetora (COLZATO et al., 2011).

O tempo de imersão para um completo revestimento é fortemente dependente da concentração de polímeros em solução, podendo este variar de alguns segundos a minutos.

\subsection{Características da cobertura formada}

Em condições ideais, a consolidação da cobertura como uma membrana rígida se dá essencialmente através da evaporação do solvente, promovendo a autoorganização do material polimérico depositado ou sua "cura". Por cura entendemos o processo de formação de ligações cruzadas ou de hidrogênio entre as cadeias poliméricas, levando a uma reticulação e à formação de uma matriz consistente. Na cura, temos a etapa de gelificação, na qual a deposição passa de um líquido viscoso a um gel elástico (MANSON e SPERLING, 1976). Após a gelificação, o processo segue mais lentamente.

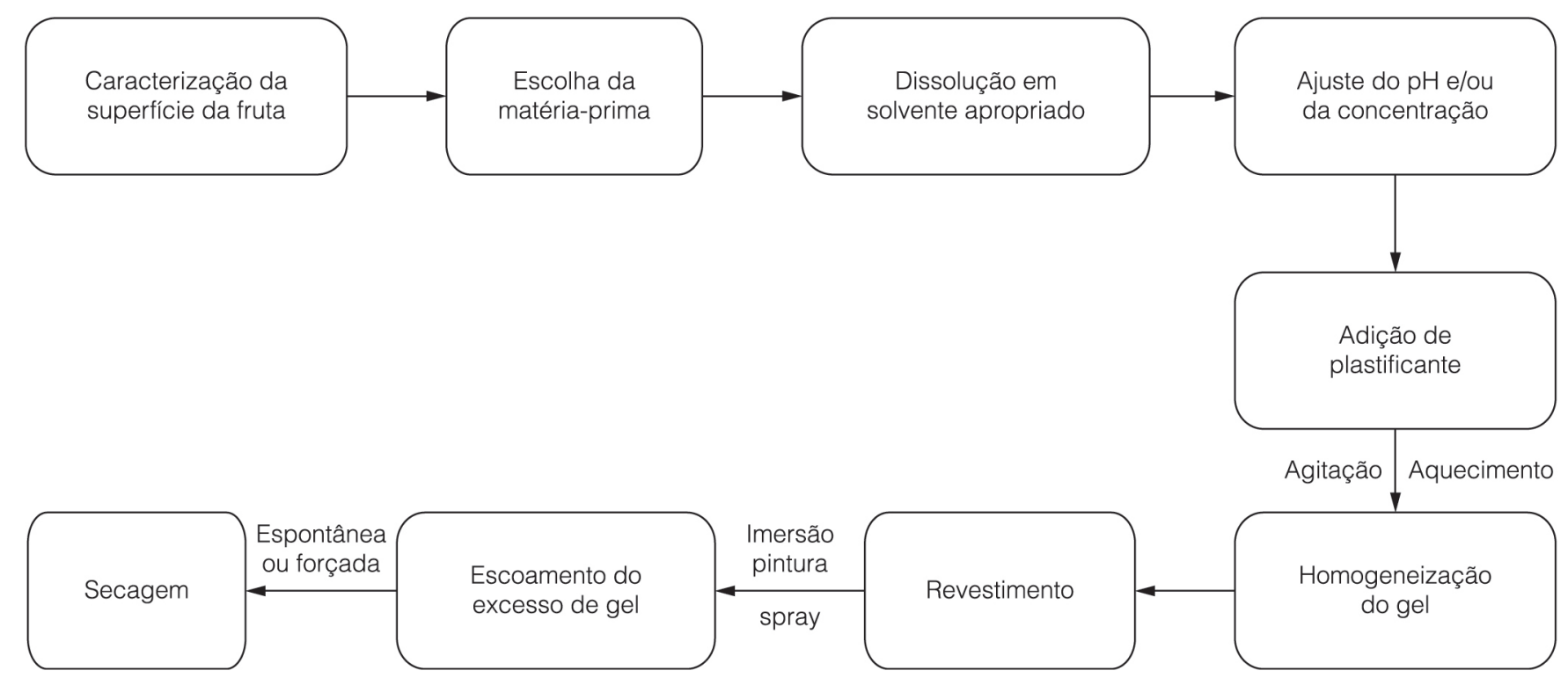

Figura 3. Sequência prática empregada na formação de cobertura comestível sobre frutas. 
Revisão: coberturas comestíveis protetoras em frutas: fundamentos e aplicações

ASSIS, O. B. G. e BRITTO, D.

A evaporação contínua do solvente leva a um aumento na densidade das ligações e um enrijecimento da matriz.

Por fim, na condição ideal, temos uma membrana delgada fortemente reticulada e aderida sobre a cutícula (para frutos intactos), ou sobre as estruturas celulósicas da polpa (para faces fatiadas), configurando uma camada adicional e de permeabilidade diferenciada. É desejável, neste processo, que a evaporação do solvente se dê de forma espontânea e o mais lentamente possível. Uma evaporação acelerada leva à formação de microbolhas, resultando muitas vezes em uma cobertura porosa e com propriedades de barreira reduzidas (STEWARD et al., 2000).

Observações realizadas por Microscopia de Força Atômica (AFM) diretamente nas coberturas ou em réplicas indicam que, para a maioria das deposições com evaporação espontânea, tem-se a formação se uma matriz de baixa porosidade, com superfície exterior ondulada. A espessura varia de alguns nanômetros a dezenas de micra, dependendo da região depositada, da rugosidade local e das características dos polímeros. Como exemplo, a Figura 4 ilustra o aspecto superficial, bidimensional e tridimensional, de uma cobertura extremamente fina de quitosana formada sobre uma maçã, segundo imagens obtidas por AFM na unidade da Embrapa Instrumentação. Essa imagem é típica de um revestimento de quitosana e análises detalhadas indicam uma cobertura contínua, porém com poros com diâmetro médio próximo a $12 \mathrm{~nm}$ (ASSIS e BRITTO, 2011).

Poros com essas dimensões permitem a passagem de oxigênio (SALUNKHE et al., 1991), estabelecendo uma respiração aeróbica mínima, o que é desejável. Um bloqueio total da permeação de oxigênio levaria a uma respiração anaeróbica, o que resultaria em um processo de fermentação interna com alterações significativas de aroma e sabor, em curto espaço de tempo.
Análises microscópicas de coberturas de composições diversas têm sido realizadas, indicando que características estruturais, como a espessura e as permeabilidades finais, estão relacionadas à composição e à concentração do polímero em solução (ROJASGRAÜ et al., 2007; SKURTYS et al., 2010). Do ponto de vista macroscópico, as coberturas devem apresentar certas peculiaridades, como ser invisíveis e ter aderência suficiente para não serem removidas no manuseio e não introduzir alterações nas características organolépticas, ou seja, preservarem principalmente o gosto ou os odores originais. Nesse sentido, diversas avaliações sensoriais têm sido realizadas indicando a boa aceitação das coberturas ou mesmo a não percepção de sua presença pelos julgadores (JORGE, 2010).

Com respeito às características biológicas, deve-se ter em mente que, quando uma fruta é colhida, há uma interrupção no equilíbrio fisiológico original. Nesta nova condição, as células internas não são mais renovadas e há uma mudança do padrão de atividade respiratória. Para as frutas com características climatéricas, além de um período de proporcional aumento da respiração, há uma maior produção de $\mathrm{CO}_{2}$ e uma geração autocatalítica de etileno $\left(\mathrm{C}_{2} \mathrm{H}_{4}\right)$, o que provoca uma aceleração metabólica levando a fruta a um gradual amadurecimento e consequente senescência. Nesta etapa, a temperatura, a umidade relativa e a forma de manuseio são decisivas.

Segundo Calbo e Nery (1994), neste estágio, os volumes gasosos intercelulares formados durante o desenvolvimento dos tecidos têm um efeito relevante na difusão de $\mathrm{CO}_{2}, \mathrm{C}_{2} \mathrm{H}_{4}$ e outros gases para o interior das células, caracterizando o processo de respiração. Já as trocas gasosas ocorrem quando se estabelece um equilíbrio entre as quantidades de $\mathrm{O}_{2}$ presentes na fase líquida das células e $\mathrm{O}_{2}$ na fase gasosa dos volumes intercelulares. Em geral, os tecidos dermais são

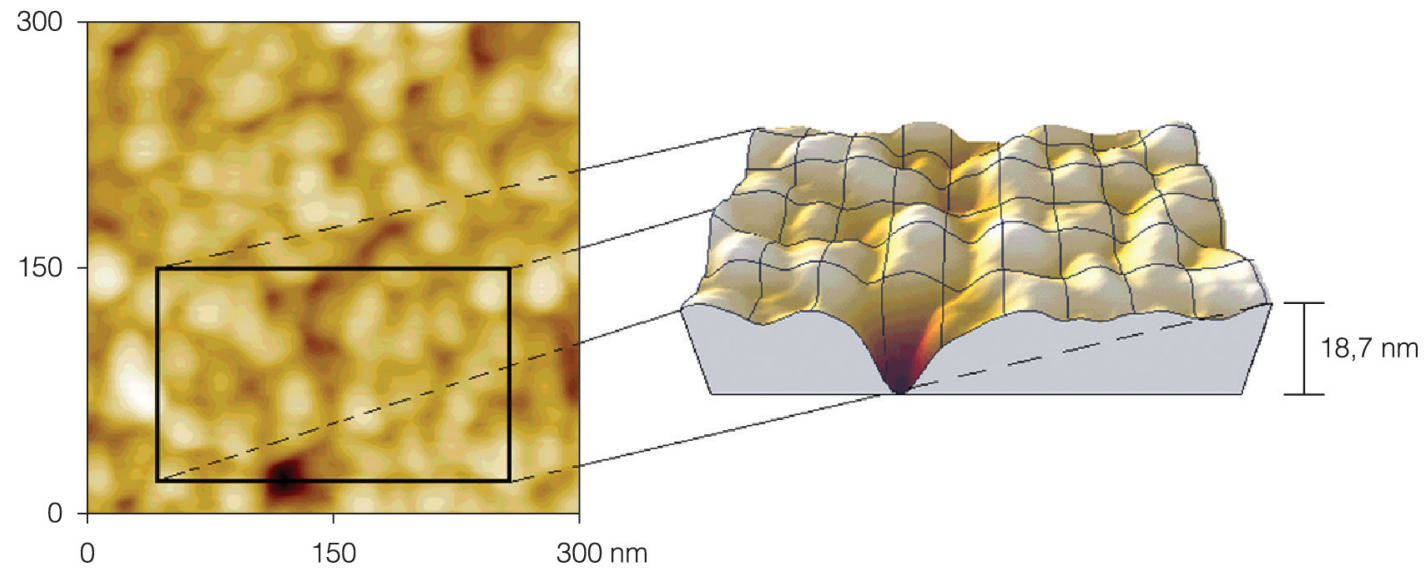

Figura 4. Superfície de uma cobertura comestível de quitosana na concentração de $2,0 \mathrm{gL}^{-1}$ em vista superior e projeção 3D da região assinalada, segundo análise por Microscopia de Força Atômica. Nota-se a presença de poros e uma topografia ondulada na escala nanométrica. 
semi-impermeáveis, reduzindo a difusão gasosa, vindo esta a ocorrer predominantemente por aberturas de estômatos, lenticelas, regiões de rompimento peduncular e, principalmente, em ferimentos na epiderme.

Neste sentido, a aplicação de revestimentos tem um papel relevante. O filme formado, além de reduzir a permeação dos tecidos intactos, promove o preenchimento parcial dessas aberturas ou ferimentos presentes no tecido dermal, atuando significativamente na redução da transferência de umidade (transpiração) e nas trocas gasosas (respiração), o que minimiza a velocidade de maturação. Como o início do processo de maturação está estreitamente associado a um aumento na produção de etileno e considerando-se que $\mathrm{O}_{2}$ exógeno é necessário para a esta produção, a redução da permeação de $\mathrm{O}_{2}$ para o interior da fruta acarretará em uma correspondente redução na produção de etileno (WATADA e QI, 1999), o que permite, em princípio, prolongar a vida da fruta.

Simultaneamente, para as frutas de coloração inicial predominantemente verde, temos uma alteração de cor como indicativo natural do amadurecimento. Ou seja, durante o amadurecimento, a clorofila se degrada nos cloroplastos formando um aglomerado de catabólitos incolores, expondo os carotenoides como os principais pigmentos responsáveis pelo amarelecimento típico do amadurecimento (STREIT et al., 2005). A degradação da clorofila pode ser acelerada pela presença de sistemas oxidantes, como o livre contato com $\mathrm{O}_{2}$ atmosférico (BLEINROTH et al., 1992). Assim, coberturas que atuam como barreira ao $\mathrm{O}_{2}$ também contribuem para redução das alterações de coloração ao longo do tempo. Em alguns produtos, a desidratação superficial é a principal responsável pela alteração de cores e pela fuga de solutos. Esse fenômeno se traduz na perda de massa, o que geralmente ocorre pela saída na forma de vapor de água para o meio circundante.

A proteção proporcionada pelo revestimento é particularmente relevante também na prevenção de infestação por micro-organismos. Como salientado por Luengo (2009), a maioria dos micro-organismos que colonizam os tecidos de frutas é constituída por fungos e bactérias "oportunistas" com características necrófagas, ou seja, não têm a capacidade isolada de penetração e fazem uso de aberturas e injúrias superficiais para colonizarem os tecidos internos.

Tabela 1. Exemplos de frutas na condição intacta e fatiada, alguns materiais empregados na formação da cobertura protetora e prolongamento da vida útil, segundo dados publicados na literatura.

\begin{tabular}{|c|c|c|c|c|c|}
\hline Fruta & $\begin{array}{c}\text { Cobertura (Principal } \\
\text { constituinte) }\end{array}$ & Condição & $\begin{array}{c}\text { Temperatura } \\
\left({ }^{\circ} \mathbf{C}\right)\end{array}$ & $\begin{array}{c}\text { Prolongamento } \\
\text { (dias) }\end{array}$ & Referência \\
\hline \multirow[t]{4}{*}{ Maçã } & alginato/goma gelana & fatiada & 25 & 2 & Rojas-Graü et al. (2007) \\
\hline & quitosana & fatiada & 5 & 6 & Pilon et al. (2013) \\
\hline & alginato & intacta & 20 & 49 & Moldão-Martins et al. (2003) \\
\hline & caseína/goma gelana & intacta & 4 & 30 & Javanmard (2011) \\
\hline \multirow[t]{3}{*}{ Papaia } & fécula de mandioca & intacto & 20 & 14 & Castricini et al. (2012) \\
\hline & quitosana & intacto & 25 & 6 & Dotto et al. (2008) \\
\hline & alginato/CMC* & fatiado & 5 & 6 & Trigo et al. (2012) \\
\hline \multirow[t]{2}{*}{ Abacaxi } & alginato/goma gelana & fatiado & 10 & 10 & Azarakhsh et al. (2012) \\
\hline & fécula de mandioca & fatiado & 5 & 8 & Bierhals et al. (2011) \\
\hline \multirow[t]{2}{*}{ Uva } & babosa (Aloe) & intacta & 1 & 21 & Valverde et al. (2005) \\
\hline & gelatina e amido & intacta & 5 & 10 & Fakhouri et al. (2007) \\
\hline \multirow[t]{3}{*}{ Morango } & proteína de soja & Intacto & 0 & 12 & Amal et al. (2010) \\
\hline & quitosana & intacto & 4 & 21 & Ghaouth et al. (1991) \\
\hline & amido mandioca & intacto & 5 & 12 & Garcia et al. (2012) \\
\hline \multirow[t]{2}{*}{ Melão } & alginato & fatiado & 5 & 14 & Raybaudi-Massilia et al. (2008) \\
\hline & quitosana & fatiado & 10 & 15 & Krasaekoopt e Mabumrung (2008) \\
\hline \multirow[t]{2}{*}{ Goiaba } & quitosana/amido & intacta & 22 & 12 & Soares et al. (2011) \\
\hline & celulose/carnaúba & intacta & 20 & 5 & McGuire e Hallman (1995) \\
\hline \multirow[t]{2}{*}{ Pera } & alginato & fatiada & 4 & 14 & Oms-Oliu et al. (2008) \\
\hline & amido & fatiada & 7 & 6 & Botrel et al. (2010) \\
\hline \multirow[t]{2}{*}{ Banana } & carragina & fatiada & 5 & 5 & Bico et al. (2009) \\
\hline & quitosana & intacta & 26 & 10 & Malmiri et al. (2011) \\
\hline \multirow[t]{2}{*}{ Manga } & fécula de mandioca & intacta & 29 & 5 & Scanavaca Jr. et al. (2007) \\
\hline & quitosana & fatiada & 7 & 6 & Chien et al. (2007) \\
\hline
\end{tabular}

${ }^{*}$ Carboximetilcelulose. 
Com respeito à atividade antimicrobiana, diversos modelos de ação têm sido apresentados como passíveis de ocorrência em função das coberturas. O mais estudado e aceito tem por base a interação que ocorre entre coberturas polissacarídeas e as membranas externas dos micro-organismos; neste caso, o mecanismo se dá por interação eletrostática, de ocorrência entre grupos protonados do tipo $\mathrm{NH}_{3}^{+}$e os resíduos negativos na superfície dos micro-organismos (GOY et al., 2009).

\section{Materiais empregados como coberturas}

Os lipídios, os polissacarídeos e as proteínas de origens diversas têm sido, como mencionado, as matériasprimas mais comumente empregadas na formação das coberturas comestíveis sobre frutas, seja com o objetivo de reduzir a respiração ou na formação de uma barreira antimicrobiana. Cada um desses materiais, isolados ou combinados, apresenta vantagens e desvantagens específicas na forma de coberturas (BALDWIN et al., 1995). Assim, variações nas concentrações e adição de plastificantes e antioxidantes têm sido práticas comuns na busca de formulações que gerem uma maior eficiência dos revestimentos formados.

A Tabela 1 exemplifica algumas aplicações, indicando o prolongamento do tempo de vida de algumas frutas, na condição intacta e fatiada, quando revestidas. Esses dados são apenas exemplos ilustrativos de uma breve busca, não representando a totalidade das publicações encontradas no assunto.

O que se depreende de concreto a partir da Tabela 1 é que não há uma formulação que satisfaça todas as condições ou que possa ser aplicada de forma universal em todas as frutas. Cabe salientar que cada fruta apresenta uma fisiologia própria, como taxa de respiração, maturação e senescência, caracterizando-se como única do ponto de vista da elaboração de um revestimento adequado. Outro aspecto a ser observado é que a cobertura não prescinde do emprego do frio. Na maioria dos exemplos apresentados e, principalmente, para os produtos minimamente processados, combinações de polímeros com antioxidantes quase sempre se fazem necessárias (VARGAS et al., 2008) e a presença do frio é imprescindível para uma plena conservação na condição apropriada ao consumo.

\section{Conclusão}

A qualidade de um produto natural depende de vários fatores, entre os quais as propriedades organolépticas e nutricionais, e as condições de higiene, muitas dessas relacionadas com o armazenamento e a comercialização. O emprego de coberturas e revestimentos comestíveis protetores, embora seja ainda um processo em desenvolvimento, tem apresentado, nas últimas décadas, resultados bastante significativos, como uma prática auxiliar na conservação de produtos perecíveis e, principalmente, daqueles minimamente processados, cujo tempo de prateleira é consideravelmente reduzido em função dos processos aos quais esses produtos foram submetidos. Como citado neste texto, as características de uma cobertura, para que responda de forma satisfatória como barreira, dependem não somente do material em si, mas igualmente do produto a ser revestido, cuja fisiologia tem um papel relevante nas condições de conservação. Com o surgimento de novos biopolímeros, com o aumento dos grupos de pesquisas voltados a este tema e, principalmente, com o interesse do setor produtivo e de logística no emprego dessa nova tecnologia, espera-se que o uso de revestimentos comestíveis venha a se constituir brevemente em uma prática corrente a ser empregada de média a larga escala na conservação de produtos, principalmente aqueles de origem tropical.

\section{Agradecimentos}

À Embrapa (Rede AgroNano) e ao CNPq, pelos auxílios recebidos.

\section{Referências}

AMAL, S. H. A.; EL-MOGY, M. M.; ABOUL-ANEAN, H. E.; ALSANIUS, B. W. Improving strawberry fruit storability by edible coating as a carrier of thymol or calcium chloride. Journal of Horticultural Science \& Ornamental Plants, Deira, v. 2, n. 3, p. 88-97, 2010.

ANDRADE, R. D.; SKURTYS, O.; OSORIO, F. A. Atomizing spray systems for application of edible coatings. Comprehensive Reviews in Food Science and Food Safety, Chicago, v. 11, n. 3, p. 323-337, 2012. http://dx.doi.org/10.1111/j.15414337.2012.00186.x

ASSIS, O. B. G. Características físico-químicas de coberturas comestiveis sobre frutas e hortaliças. In: JORNADAS INTERNACIONAIS SOBRE AVANÇO DA TECNOLOGIA DE FILMES E COBERTURAS FUNCIONAIS EM ALIMENTOS, 3.; JORNADA DA AGROBIO ENVASES, 3., 2011, Campinas. Anais... Campinas: UNICAMP, 2011. p. 20-21.

ASSIS, O. B. G.; SILVA, V. L. Caracterização estrutural e da capacidade de absorção de água em filmes finos de quitosana processados em diversas concentrações. Polímeros: Ciência e Tecnologia, São Carlos, v. 13, n. 4, p. 223-228, 2003.

ASSIS, O. B. G.; FORATO, L. A.; BRITTO, D. Revestimentos comestíveis protetores em frutos minimamente processados. Higiene Alimentar, São Paulo, v. 22, n. 160, p. 99-106, 2008.

ASSIS, O. B. G.; BRITTO, D. Evaluation of the antifungal properties of chitosan coating on cut apples using a non-invasive image analysis technique. Polymer International, London, v. 60, n. 6, p. 932-936, 2011. http://dx.doi.org/10.1002/pi.3039 
Revisão: coberturas comestíveis protetoras em frutas: fundamentos e aplicações ASSIS, O. B. G. e BRITTO, D.

AZARAKHSH, N.; OSMAN, A.; GHAZALI, H. M.; TAN, C. P.; MOHD-ADZAHAN, N. Optimization of alginate and gellanbased edible coating formulations for fresh-cut pineapples. International Food Research Journal, Selangor, v. 19, n. 1, p. 279-285, 2012.

BALDWIN, E. A.; NISPEROS-CARRIEDO, M. O.; BAKER, R. A. Edible coatings for lightly processed fruits and vegetables. HortScience, Alexandria, v. 30, n. 1, p. 35-38, 1995.

BANKER, G. S. Film coating theory and practice. Journal of Pharmaceutical Sciences, Whashington, v. 55, n. 1, p. 81-89, 1966.

BARBOSA-CÁNOVAS, G. V.; FRENÁNDEZ-MOLINA, J. J.; ALZAMORA, S. M.; TAPIA, M. S.; LÓPEZ-MALO, A.; CHANES, J. W. Handling and preservation of fruits and vegetables by combined methods for rural areas. Roma: FAO, 2003. 99 p. (Technical Manual).

BICO, S. L. S.; RAPOSO M. F. J.; MORAIS, R. M. S. C.; MORAIS, A. M. M. B. Combined effects of chemical dip and/or carrageenan coating and/or controlled atmosphere on quality of fresh-cut banana. Food Control, Amsterdam, v. 20, n. 5, p. 508-514, 2009. http://dx.doi.org/10.1016/j.foodcont.2008.07.017

BIERHALS, V. S.; CHIUMARELLI, M.; HUBINGER, M. D. Effect of cassava starch coating on quality and shelf life of fresh-cut pineapple (Ananas comosus L. Merril cv "Pérola"). Journal of Food Science, Chicago, v. 76, n. 1, p. E62-E72, 2011. PMid:21535677. http://dx.doi.org/10.1111/j.17503841.2010.01951.x

BLEINROTH, E. W.; SIGRIST, J. M. M., ARDITO, E. F. G.; CASTRO, J. V.; SPAGNOL, W. A.; NEVES-FILHO, L. C. Tecnologia pós-colheita de frutas tropicais. Campinas: ITAL, 1992. 203 p. (Manual Técnico, 9).

BOtREL, D. A.; SOARES, N. F. F.; CAMILLOTO, G. P.; FERNANDES. R. V. B. Revestimento ativo de amido na conservação pós-colheita de pera Williams minimamente processada. Ciência Rural, Santa Maria, v. 40, n. 8, p.1814-1820, 2010. http://dx.doi.org/10.1590/S0103-84782010000800023

CALBO, A. G.; NERY, A. A. Methods to measure gaseous volume in plants. Revista Brasileira de Fisiologia Vegetal, Brasília, v. 6, n. 2, p. 153-162, 1994.

CASTRICINI, A.; CONEGLIAN, R. C. C.; DELIZA. R. Starch edible coating of papaya: effect on sensory characteristics. Ciência e Tecnologia dos Alimentos, Campinas, v. 32, n. 1, p. 84-92, 2012.

CHIEN, P-J.; SHEU, F.; YANG, F-H. Effects of edible chitosan coating on quality and shelf life of sliced mango fruit. Journal of Food Engineering, Amsterdam, v. 78, n. 1, p. 225-229, 2007. http://dx.doi.org/10.1016/j.jfoodeng.2005.09.022

CHITARRA, M. I. F.; CHITARRA, A. B. Pós-colheita de frutas e hortaliças: fisiologia e manuseio. 2. ed. Lavras: Editora UFLA, 2005.
CHLEBOWSKA-SMIGIEL, A.; GNIEWOSZ, M.; SWINCZAK, E. An attempt to apply a pullulan and pullulan-protein coatings to prolong apples shelf-life stability. Acta Scientiarum Polonorum Technologia Alimentaria, Poznan, v. 6, n. 1, p. 49-56, 2007.

COLZATO, M.; SCRAMIN, J. A.; FORATO, L. A.; COLNAGO, L. A.; ASSIS, O. B. G. H NMR Investigation of oil oxidation in macadamia nuts coated with zein-based films. Journal of Food Processing and Preservation, Westport, v. 35, n. 6, p. 790-796, 2011. http://dx.doi.org/10.1111/j.1745-4549.2011.00530.x

COSTA, J. M. C. da; CLEMENTE, E. Refrigeration and cold chain effect on fruit shelf life. In: RODRIGUES, S.; FERNANDES, F. A. N. (Ed.). Advances in fruit processing technologies. Boca Taton: CRC Press, 2012. p. 287-330. http://dx.doi.org/10.1201/ b12088-13

DOtTO, G. L.; GREVINELI, A. C.; OLIVEIRA, A.; PONS, G.; PINTO, L. A. A. Uso de quitosana como filme microbiológico para o aumento da vida útil de mamões papaia. In: CONGRESSO DE INICIAÇÃO CIENTÍFICA E ENCONTRO DE PÓS-GRADUAÇÃO, 17., 2008, Pelotas. Anais eletrônicos... Pelotas: Universidade Federal de Pelotas, 2008. Disponível em <www.ufpel.edu.br/ cic/2008/cd/pages/pdf/CA.> Acesso em: 26 novembro 2013.

FAKHOURI, F. M.; FONTES, L. C. B.; GONÇALVES, P. V. M.; MILANEZ, C. R.; STEEL, C. J.; COLLARES-QUEIROZ, F. P. Filmes e coberturas comestíveis compostas à base de amidos nativose gelatina na conservação e aceitação sensorial de uvas Crimson. Ciência e Tecnologia dos Alimentos, Campinas, v. 27, n. 2 , p. 369-375, 2007.

FOOD AND DRUG ADMINISTRATION - FAD. Generally recognized as safe (GRAS). Silver Spring. Disponível em: <http://www.fda.gov/Food/IngredientsPackagingLabeling/ GRAS/>. Acesso em: 5 novembro 2013.

GARCIA, L. C.; PEREIRA, L. M.; SARANTÓPOULOS, C. I. G. L.; HUBINGER M. D. Effect of antimicrobial starch edible coating on shelf-life of fresh strawberries. Packaging Technology and Science, Hoboken, v. 25, n. 7, p. 413-425, 2012. http://dx.doi. org/10.1002/pts.987

GHAOUTH, A.; ARUL, J.; PONNAMPALAM, R.; BOULET, M. Chitosan coating effect on storability and quality of fresh strawberries. Journal of Food Science, Chicago, v. 56, n. 6, p. 1618-1620, 1991. http://dx.doi.org/10.1111/j.1365-2621.1991. tb08655.x

GOY, R. C.; BRITTO, D.; ASSIS, O. B. G. A review of the antimicrobial activity of chitosan. Polímeros: Ciência e Tecnologia, São Carlos, v. 19, n. 3, p. 241-247, 2009.

HARALAMPU, S. G. Protein-based edible coatings. Patent US PCT/US90/06441, 1990.

HERZFELD, J.; OLBRIS, D. J. Hydrophobic effect. In: ENCYCLOPEDIA of Life Science. John Wiley \& Sons, 2002. Disponível em: <http://xibalba.lcg.unam.mx/ rgalindo/ 
Revisão: coberturas comestíveis protetoras em frutas: fundamentos e aplicações ASSIS, O. B. G. e BRITTO, D.

bioquimica/BQPosgrado2011/l\%20FQ\%20repaso/ HydrophobicEffect.pdf>. Acesso em: 23 outubro 2013.

JAVANMARD, M. Shelf-life of apples coated with whey protein concentrate-gellan gum edible coatings. Journal of Food Biosciences and Technology, Teran, v. 1, n. 1, p. 55-62, 2011.

JORGE, P. C. S. Avaliação de maçã 'Royal Gala' revestida com filme de quitosana durante o período de pós-colheita. Dissertação (Mestrado em Ciência dos Alimentos)-Universidade Estadual Paulista, Araraquara, 2010.

KEATS, R. A. B. Biophysical methods: lecture 2 protein interactions leading to folding. Canada: Delph University, 2000. Disponível em: <http://www.chembio.uoguelph.ca/educmat/ phy456/456lec02.htm>. Acesso em: 10 setembro 2013.

KRASAEKOOPT, W.; MABUMRUNG, J. Microbiological evaluation of edible coated fresh-cut cantaloupe. Kasetsart Journal (Natural Science), Bangkok, v. 42, n. 3, p. 552-557, 2008.

LUENGO, R. F. A. Embalagens utilizadas no Brasil. In: LUENGO, R. F. A.; CALBO, A. G. (Ed.) Embalagens para comercialização de hortaliças e frutas no Brasil. Brasília: Embrapa Hortaliças, 2009. p. 11-28.

MALMIRI, H. J.; OSMAN, A.; TAN, C. P.; RAHMAN, R. A. Development of an edible coating based on chitosan-glycerol to delay 'Berangan' banana (Musa sapientum cv. Berangan) ripening process. International Food Research Journal, Selangor, v. 18, n. 3, p. 989-997, 2011.

MANSON, J. A.; SPERLING, L. N. Polymer blends and composites. New York: Plenum Press, 1976. http://dx.doi. org/10.1007/978-1-4615-1761-0

MCGUIRE, R. G.; HALLMAN, G. J. coating guavas with celluloseor carnauba-based emulsions interferes with postharvest ripening. HortScience, Alexandria, v. 30, n. 2, p. 294-295, 1995.

MOLDÃO-MARTINS, M.; BEIRÃO-DA-COSTA, S. M.; BEIRÃODA-COSTA, M. L. The effects of edible coatings on postharvest quality of the "Bravo de Esmolfe" apple. European Food Research and Technology, Berlin, v. 217, n. 4, p. 325-328, 2003. http://dx.doi.org/10.1007/s00217-003-0761-9

MYERS, D. Surface, interfaces, and colloids: principles and applications. New York: VCH Publishers, 1991.

OMS-OLIU, G.; SOLIVA-FORTUNY, R.; MARTÍN-BELLOSO, O. Edible coatings with antibrowning agents to maintain sensory quality and antioxidant properties of fresh-cut pears. Postharvest Biology and Technology, Amsterdam, v. 50, n. 1, p. 87-94, 2008. http://dx.doi.org/10.1016/j.postharvbio.2008.03.005

PARIA, S.; KHILAR, K. C. A review on experimental studies of surfactant adsorption at the hydrophilic solid-water interface. Advances in Colloid and Interface Science, Amsterdam, v. 110, n. 3, p. 75-95, 2004. http://dx.doi.org/10.1016/j.cis.2004.03.001
PARK, H. J. Edible coatings for fruits. In: JONGEN, W. W. F. (Ed.). Fruit and vegetable processing: improving quality. Boca Raton: CRC Press, 2005. p. 331-345.

PATERNO, L. G.; MATtOSO, L. H. C.; OLIVEIRA JUNIOR, O. N. Ultrathin polymeric films produced by self-assembly: preparation, properties and applications. Química Nova, São Paulo, v. 24, n. 2, p. 228-235, 2001. http://dx.doi.org/10.1590/ S0100-40422001000200013

PELESKO, J. A. Self assembly: the science of things that put themselves. Boca Raton: Chapman and Hall: CRC Press, 2007. http://dx.doi.org/10.1201/9781584886884

PILON, L.; SPRICIGO, P. C.; BRITTO, D.; ASSIS, O. B. G.; CALBO, A. G., FERRAUdO, A. S., FERREIRA, M. D. Effects of antibrowning solution and chitosan-based edible coating on the quality of fresh-cut apple. International Journal of Postharvest Technology and Innovation, Geneve, v. 3, n. 2, p. 151-164, 2013. http://dx.doi.org/10.1504/IJPTI.2013.055843

RAYBAUDI-MASSILIA, R. M.; MOSQUEDA-MELGAR, J.; MARTÍN-BELLOSO, O. Edible alginate-based coating as carrier of antimicrobials to improve shelf-life and safety of fresh-cut melon. International Journal of Food Microbiology, Amsterdam, v. 121, n. 3, p. 313-327, 2008. PMid:18164505. http://dx.doi.org/10.1016/j.jijoodmicro.2007.11.010

RODRIGUE, J-P.; NOTTEBOOM, T. The cold chain and its logistic. In: RODRIGUE, J-P.; COMTOIS, C.; SLACK, B. The geography of transport systems. 2nd ed. New York: Routledge, 2009. 297 p. Disponível em: <http://geonas.at.ua/_ld/0/34_The_ Geography_o.pdf>

ROJAS-GRAÜ, M. A.; TAPIA, M. S.; RODRÍGUEZ, F. J.; CARMONA, A. J.; MARTIN-BELLOSO, O. Alginate and gellanbased edible coatings as carriers of antibrowning agents applied on fresh-cut Fuji apples. Food Hydrocolloids. Amsterdam, v. 21, n. 1, p. 118-127, 2007. http://dx.doi.org/10.1016/j. foodhyd.2006.03.001

SALUNKHE, D. K.; BOLIN, H. R.; REDDY, N. R. Storage methods. In: SALUNKLE, D. K. Storage, processing and nutritional quality of fruits and vegetables. Boca Raton: CRC Press, 1991. p. 243-294.

SCANAVACA Jr., L.; FONSECA, N.; PEREIRA, M. E. C. Uso de fécula de mandioca na pós-colheita de manga 'surpresa'. Revista Brasileira de Fruticultura, Jaboticabal, v. 29, n. 1, p. 67-71, 2007.

SCRAMIN, J. A.; BRITTO, D.; FORATO, L. A.; BERNARDESFILHO, R.; COLNAGO, L. A.; ASSIS, O. B. G. Characterisation of zein oleic acid films and applications in fruit coating. International Journal of Food Science \& Technology, Oxford, v. 46, n. 10, p. 2145-2152, 2011. http://dx.doi.org/10.1111/j.13652621.2011.02729.x 
Revisão: coberturas comestíveis protetoras em frutas: fundamentos e aplicações

ASSIS, O. B. G. e BRITTO, D.

SKURTYS, O.; ACEVEDO, C.; PEDRESCHI, F.; ENRIONE, J.; OSORIO, F.; AGUILERA, J. M. Food hydrocolloid edible films and coatings. New York: Nova Science Publishers, 2010.

SOARES, N. F. F.; SILVA, D. F. P.; CAMILLOTO, G. P.; OLIVEIRA, C. P.; PINHEIRO, N. M.; MEDEIROS, E. A. A. Antimicrobial edible coating in post-harvest conservation of guava. Revista Brasileira de Fruticultura, Jaboticabal, v. 33, n. 1, p. 281-289, 2011.

STEWARD, P. A.; HEARN, J.; WILKINSON, M. C. An overview of polymer latex film formation and properties. Advances in Colloid and Interface Science, Amsterdam, v. 86, n. 3, p. 195-267, 2000. http://dx.doi.org/10.1016/S0001-8686(99)00037-8

STREIT, N. M.; CANTERLE, L. P.; CANTO, M. W.; HECKTHEUER, L. H. H. As clorofilas. Ciência Rural, Santa Maria, v. 35, n. 3, p. 748-755, 2005.

TRIGO, J. M.; ALBERTINI, S.; SPOTO, M. H. F.; SARMENTO, S. B. S.; LAI REYES, A. H.; SARRIÉS, G. A. Efeito de revestimentos comestiveis na conservação de mamões minimamente processados. Brazilian Journal of Food Technology, Campinas, v. 15, n. 2, p. 125-133, 2012. http://dx.doi. org/10.1590/S1981-67232012005000005

TURHAN, K. N. Is edible coating an alternative to MAP for fresh and minimally processed fruits? Acta Horticulturae, Leuven, v. 876, n. 1, p. 299-305, 2010.
VALVERDE, J. M.; VALERO, D.; MARTÍNEZ-ROMERO, D.; GUILLÉN, F.; CASTILLO, S.; SERRANO, M. Novel edible coating based on aloe vera gel to maintain table grape quality and safety. Journal of Agricultural and Food Chemistry, Easton, v. 53, n. 20, p. 7807-7813, 2005.

VARGAS, M.; PASTOR, C.; CHIRALT, A.; MCCLEMENTS, D. J.; GONZÁLEZ-MARTÍNEZ, C. Recent advances in edible coatings for fresh and minimally processed fruits. Critical Reviews in Food Science and Nutrition, Cleaveland, v. 48, n. 6, p. 496-511, 2008.

VARGAS, M.; ALBORS, A.; CHIRALT, A.; GONZÁLEZ-MARTÍNEZ, C. Characterization of chitosan-oleic acid composite films. Food Hydrocolloids, Amsterdam, v. 23, n. 2, p. 536-547, 2009. http:// dx.doi.org/10.1016/j.foodhyd.2008.02.009

WATADA, A. E.; QI, L. Quality of fresh-cut produce. Postharvest Biology and Technology, Amsterdam, v. 15, n. 3, 201-205, 1999. http://dx.doi.org/10.1016/S0925-5214(98)00085-4

ZARITZKY, N. Edible coating to improve food quality and safety. In: AGUILERA, J. M.; SIMPSON, R.; WELTI-CHANES, J.; BERMUDEZ AGUIRRE, D.; BARBOSA-CÁNOVAS, G. (Ed.). Food engineering interfaces. New York: Springer, 2011. p. 631-660. 